\title{
Aprendizagem Baseada em Projetos: Relato de Introdução da Lógica no Ensino Fundamental
}

\author{
Lucas Tadeu Hinterholz ${ }^{1}$, Wilk Oliveira dos Santos ${ }^{2}$ \\ ${ }^{1}$ Escola Municipal de Ensino Fundamental Nossa Senhora da Glória (EMNSG) - Sinimbu - \\ RS - Brasil \\ ${ }^{2}$ Núcleo de Excelência em Tecnologias Sociais (NEES) - Instituto de Computação (IC) - \\ Universidade Federal de Alagoas (UFAL) - Maceió - AL - Brasil \\ lhinterholz@gmail.com, wos@ic.ufal.br
}

\begin{abstract}
Resumo. Este artigo relata o desenvolvimento de um Projeto de Ensino de Lógica em turma de $5^{\circ}$ ano do Ensino Fundamental de uma escola pública do município de Sinimbu/RS. A iniciativa justifica-se pela necessidade de introdução dos estudantes deste nível ao Pensamento Computacional, competência necessária na resolução de problemas de todas as áreas do conhecimento e que tem origem na área da Computação. A metodologia adotada contempla fundamentos de Lógica, organização de estudos por mapas conceituais, aplicação prática em jogos físicos e digitais, pesquisas de campo e proposta de resolução de problema. Os resultados preliminares indicam que o aproveitamento dos alunos tem aumentado ao longo das atividades.
\end{abstract}

Abstract. This paper reports the development of a Logic Teaching Project in a 5th class of Elementary School in a public school in the municipality of Sinimbu / RS. The initiative is justified by the need to introduce students of this level to Computational Thinking, a necessary competence to solving problems of all areas of knowledge and which originates in the area of Computing. The methodology adopted includes the fundamentals of Logic, organization of studies by conceptual maps, practical application in physical and digital games, field surveys and problem solving proposal. Preliminary results indicate that student skills has increased over time.

\section{Introdução}

A partir da Lei de Diretrizes e Bases (LDB) de 1996, que instituiu a Computação como elemento complementar de ensino e suporte interdisciplinar nas escolas, bem como do Plano Nacional de Educação (PNE) 2014-2024, que reforça a necessidade de ampliação dos laboratórios de informática, começa a ser formado um novo cenário para a Computação na Educação Básica. Mesmo que de forma tardia, esses movimentos começam a convergir com a convicção de Papert (1985), que já acreditava que a construção do conhecimento do aluno deveria ter o suporte do computador em sala de aula. Esta evolução, de acordo com Silva et al. (2015), tem sido contemplada especialmente pelo aumento nos projetos advindos do curso 
VI Congresso Brasileiro de Informática na Educação (CBIE 2017)

Anais do XXIII Workshop de Informática na Escola (WIE 2017)

de Licenciatura em Computação, que tem como uma das suas vertentes principais formar profissionais capazes de ensinar Computação enquanto ciência, no contexto da Educação Básica.

Em proximidade a este ideal, o Município de Sinimbu no Rio Grande do Sul inseriu em uma de suas escolas municipais a disciplina de Computação para as turmas de quarto e quinto ano do Ensino Fundamental. Mesmo não sendo disciplina que faça parte da grade curricular oficial da escola, a Computação nesta escola dá suporte a professores e alunos de todos os anos e áreas; para as duas turmas já citadas, é utilizada em Projetos de Ensino.

O projeto ora descrito parte da necessidade da formação de um novo tipo de estudante, capaz de resolver problemas complexos cotidianos, sendo o Pensamento Computacional, de acordo com Rodrigues et al. (2015) capaz de auxiliar no desenvolvimento desta habilidade. Segundo Blikstein (2008), esta competência tem relação direta com a capacidade cognitiva de refinar o pensamento lógico e abstrato; resume-se na habilidade de resolver problemas do cotidiano a partir do conhecimento das teorias da Computação, como, melhor escolha, escalonamento de dados, alocação de memória, armazenamento e teoria da Lógica.

Ao mesmo tempo, segundo o FNDE, quase $40 \%$ dos estudantes dos anos finais do Ensino Fundamental que prestaram a Prova Brasil entre 2005 e 2009 não apresentaram o nível básico de conhecimento de resolução de problemas esperado para esta faixa de escolaridade; índice que o mesmo afirma permanecer estável nos últimos anos. Ou seja, pouco mais da metade dos estudantes que estão ingressando no Ensino Médio não têm plena capacidade cognitiva de analisar e resolver alguma situação por abstração e/ou decomposição.

Diante desta situação complexa, este trabalho relata o ensino de Lógica em uma turma de $5^{\circ}$ ano do Ensino Fundamental da EMEF Nossa Senhora da Glória, localizada no município de Sinimbu no Rio Grande do Sul, por meio de um Projeto de Ensino para o incentivo ao Pensamento Computacional, intitulado "Pensando \& Resolvendo". O projeto dá-se através de uma construção coletiva entre professor e alunos nas fases de planejamento e execução - exceto, na definição do tema e objetivos. O projeto visa promover o Pensamento Computacional dos estudantes por meio da resolução de problemas cotidianos, utilizando como instrumento a realização de atividades como o desenvolvimento de jogos físicos e virtuais, saídas de campo e pesquisas. Os resultados iniciais indicam que as atividades têm sido aceitas pelos estudantes, bem como melhorando seu aproveitamento escolar.

\section{Revisão da Literatura}

Esta seção apresenta a revisão da literatura utilizada como referência para este trabalho de aplicação.

\subsection{Pensamento Computacional e Computação Desplugada}

A competência do pensamento computacional é produto do mundo globalizado. Segundo Rodrigues et al. (2015), o grande fluxo de informações que precisamos processar diariamente em nosso trabalho ou estudo implica na necessidade de um cérebro treinado e com grande capacidade de abstração. Para Nunes (2011), esta competência significa estimular o cérebro a trabalhar de forma sistêmica e segmentar, ordenando o pensamento como em uma 
VI Congresso Brasileiro de Informática na Educação (CBIE 2017)

Anais do XXIII Workshop de Informática na Escola (WIE 2017)

sequência de passos até uma resolução. Este "pensamento" é chamado de computacional, pois, tem relação direta com as teorias da Ciência da Computação de escalonamento de dados, alocação de memória, algoritmos e outros.

Ainda segundo Nunes (2011), o pensamento computacional é interdisciplinar, aplicando-se a todas as áreas do conhecimento. Por exemplo, para calcular ou mesmo organizar um texto, ou ainda, para escolher o melhor trajeto de casa a escola, considerando diferentes fatores, como segurança, distância, etc., é preciso ter capacidade de raciocínio lógico e abstração. Assim, o pensamento computacional é uma competência de aplicação geral e é importante que se condicione o estudante desde as etapas iniciais de formação.

Com o intuito de estimular este Pensamento Computacional, diferentes ferramentas e recursos têm sido utilizados. Raabe et al. (2015) define, através de meta-análise de dados, as principais ferramentas utilizadas para ensino do Pensamento Computacional na atualidade. Sua pesquisa indica que é no Ensino Fundamental onde são mais utilizadas essas ferramentas, com destaque para a ferramenta Scratch - linguagem de programação gráfica e pelo uso de atividades de "Computação Desplugada" - conceito que sugere o ensino de computação para crianças através de meios não-convencionais e dissociados da utilização do computador - especialmente as atividades contidas na publicação Computer Science Unplugged; publicado em 2007 por Tim Bell. As atividades do livro Computer Science Unplugged são o cerne do plano de trabalho do Projeto de Ensino descrito neste artigo.

\section{Metodologia e Aplicação}

A metodologia utilizada consiste em ministrar aulas em sala de aula convencional e no laboratório de Informática, onde os alunos participam de forma colaborativa em partes específicas da construção das atividades, guiados pelo professor e observadas as suas capacidades e limitações. Em decorrência do curto tempo do período de aula, acontecem paralelamente encontros semanais no turno oposto, estes, com duração de um turno inteiro.

As atividades do projeto foram organizadas da seguinte forma: $(i)$ as aulas do projeto com a introdução dos fundamentos de Lógica e demais atividades ocorrem durante o ano letivo - duzentos dias - com turma de quinto ano do Ensino Fundamental. Os encontros acontecem no período regular das aulas, quase que na totalidade em sala de aula convencional; eventualmente, é necessária a utilização do computador junto ao laboratório de Informática da escola; (ii) as atividades desenvolvidas em sala de aula no contexto da Lógica articulam-se ao pensamento computacional por meio da confecção de jogos físicos e virtuais - com PowerPoint - e proposta de resolução de problema.

O projeto está organizado em dez fases segmentadas cronologicamente, e dividas em dois grupos principais, como apresentado a seguir ${ }^{1}$ : No primeiro grupo, (i) projeto e mapas conceituais: estudo da definição de projeto englobando todas as suas caraterísticas e organização de estudos através de mapas conceituais; (ii) Definição dos objetivos: elencados por professor e alunos ao começo do ano letivo; (iii) Introdução a pesquisa: estudo da definição de pesquisa e aspectos da pesquisa científica; (iv) Produção de pesquisa com mapas conceituais: pesquisa realizada pelos alunos com o tema $O$ que é pesquisa? e

\footnotetext{
${ }^{1}$ Cronograma do projeto: https://goo.gl/sYYEyg
} 
VI Congresso Brasileiro de Informática na Educação (CBIE 2017)

Anais do XXIII Workshop de Informática na Escola (WIE 2017)

apresentada com mapa conceitual; (v) Ensino de lógica: O ensino de Lógica foi introduzida de forma prática através de jogos que os próprios alunos desenvolveram.

Tratam-se de jogos de diagrama e de preenchimento de espaços seguindo dicas e procedimentos por premissas;

No segundo grupo, (vi) Produção de jogos: os jogos foram desenvolvidos utilizando a ferramenta PowerPoint, que permite a criação de jogos de diagramas e preenchimento de espaços, por meio de lógica simples, com abstração de itens complexos; (vii) Pesquisa de campo: saídas com a turma para verificar situações a serem otimizadas no próprio município, relativos à organização do trânsito, vias de acesso e circulação ou outros; (viii) Análise de dados: revisão, organização e interpretação das informações colhidas pelos alunos em campo para propor a resolução de problema escolhido coletivamente; (ix) Apresentação: divulgação do projeto, proposta, resultados e atividades desenvolvidas para a comunidade escolar na mostra de final de ano, e; $(x)$ Relatório no blog: o blog foi escolhido como ferramenta de divulgação online do projeto. Nele, são registradas todas as atividades realizadas em aula e nos encontros de turno oposto. As principais imagens ${ }^{2}$ relacionadas ao projeto podem ser encontradas no link presente na segunda nota de rodapé deste artigo, bem como, o endereço do $b \log ^{3}$.

Até o presente momento, as atividades $i$, ii, iii e $i v$ foram concluídas com sucesso, sendo que, $v$ e $x$ estão em andamento. A finalização do projeto (no mês de dezembro) prevê que os alunos, após levantamento de dados, escolham um problema encontrado no município e proponham uma resolução real, seja ela por meios tecnológicos digitais ou não. A intenção é que se utilize do conhecimento de lógica e do pensamento abstrato - que se espera ter despertado - aplicado a uma solução para algum determinado problema em qualquer segmento como trânsito, acesso e circulação de pessoas, acessibilidade, entre outras possibilidades.

\section{Considerações Finais}

Este artigo apresentou as atividades desenvolvidas em Projeto de Ensino, atualmente aplicado à turma de $5^{\circ}$ ano do Ensino Fundamental, como forma de incentivo ao pensamento computacional pela computação desplugada. O objetivo foi o fazer com que os estudantes fossem os mais autônomos possível na construção de seu conhecimento, embora, deva ser esta uma marca de Projetos de Aprendizagem.

Os resultados preliminares indicam que os conteúdos a atividades têm sido amplamente aceitos pelos estudantes, mantendo-os motivados no desenvolvimento do projeto. Ao mesmo tempo, os estudantes têm demonstrado evolução em termos de raciocínio lógico, como pode ser avaliado a partir das atividades de desenvolvimento de jogos, confirmando assim aquilo que já dizia Papert (1994), "permitir que os estudantes criem seu próprio material pedagógico os reverte de objeto para sujeito de seu conhecimento".

Os principais resultados do projeto indicam forte adesão dos estudantes ao projeto, e melhoria na capacidade de abstração dos mesmos. É expectativa dos autores que este relato

\footnotetext{
${ }^{2}$ Imagens do projeto: https://goo.gl/wXXfPF

${ }^{3}$ Endereço do blog: https://goo.gl/fPkamm
} 
VI Congresso Brasileiro de Informática na Educação (CBIE 2017)

Anais do XXIII Workshop de Informática na Escola (WIE 2017)

motive professores a continuarem buscando o espaço da computação nos currículos escolares e que incentivem ações de promoção ao pensamento computacional na sala de aula através da computação desplugada. Como trabalhos futuros, vislumbra-se ainda a incorporação dos projetos a novas turmas, trabalhando de forma multidisciplinar com professores das diferentes disciplinas que compõem o currículo da educação básica.

\section{Referências}

Bell, T. C., Witten, I. H., \& Fellows, M. (1998). Computer Science Unplugged: Off-line activities and games for all ages. Computer Science Unplugged.

Blikstein, P. (2008). Opensamento computacional e a reinvenção do computador na educação.

Bombasar, J., Raabe, A.,de Miranda, E. M., \& Santiago, R. (2015, October). Ferramentas para oensino-aprendizagem do pensamento computacional: onde está alan turing?. In Brazilian Symposium on Computers in Education (Simpósio Brasileiro de Informática na Educação-SBIE) (Vol. 26, No. 1, p. 81).

Brasil. Fundo Nacional de Desenvolvimento da Educação - FNDE . http://cursos.fnde.gov.br/mdl07/file.php/44092/PDF_da_Unidade_II.pdf Acesso: Junho, 2017.

Brasil. Ministério da Educação - MEC. (1996) "Lei de Diretrizes e Bases da Educação Nacional - LDB”. http://www.planalto.gov.br/ccivil_03/leis/L9394.htm, Acesso em: Maio, 2017.

Brasil. Ministério da Educação - MEC. "Planejando a próxima década: conhecendo as 20 metas do Plano Nacional de Educação”. (2014) http://pne.mec.gov.br/images/pdf/pne_conhecendo_20_metas.pdf, Maio.

Nunes, Daltro. (2011) "Ciência da Computação na Educação Básica", http://www.adufrgs.org.br/artigos/ciencia-da-computacao-na-educacao-basica/.

Papert, S. (1985) Logo: computadores e educação. São Paulo: Brasiliense.

Papert, S. (1994). A máquina das crianças: repensando a escola na era digital. Artmed. Ed.

Referenciais de Formação em Computação, Cap. V "Referenciais de Formação em Computação: Licenciatura em Computação". (2017) http://www.sbc.org.br/noticias/10slideshow-noticias/1979-consulta-publica-sobre-osreferenciais-de-formacao-emComputação-da-sbc, Maio.

Rodriguez, C., Zem-Lopes, A. M., Marques, L., \& Isotani, S. (2015, October). Pensamento Computacional: transformando ideias em jogos digitais usando o Scratch. In Anais do Workshop de Informática na Escola (Vol. 21, No. 1, p. 62).

Silva, S.F., Ferreira, A., Souza, A.A., Galdino, E., Oliveira, M.L.S., Neto, S. e Oliveira, W. (2015) "Relato de Experiência de Ensino de Computação no Ensino Fundamental em Estágio Supervisionado da Universidade de Pernambuco no Campus Garanhuns", In: $23^{\circ}$ Workshop sobre Educação em Computação, p. 1-10. 